\title{
Comparative transcriptomic analysis of Listeria monocytogenes reveals upregulation of stress genes and downregulation of virulence genes in response to essential oil extracted from Baccharis psiadioides
}

\author{
Luiza Pieta $^{1}$ - Frank Lino Guzman Escudero ${ }^{2}$ - Ana Paula Jacobus ${ }^{3}$. \\ Kamila Patikowski Cheiran ${ }^{1}$. Jeferson Gross ${ }^{3}$. Maria Lisseth Eguiluz Moya ${ }^{4}$. \\ Geraldo Luiz Gonçalves Soares ${ }^{5}$ Rogério Margis ${ }^{2,4}$ • Ana Paula Guedes Frazzon ${ }^{6}$ • \\ Jeverson Frazzon ${ }^{1}$
}

Received: 3 March 2017 / Accepted: 8 May 2017 /Published online: 28 May 2017

(C) Springer-Verlag Berlin Heidelberg and the University of Milan 2017

\begin{abstract}
Listeria monocytogenes is a pathogenic microorganism in humans and is frequently transmitted by food. Methods to control the presence of Listeria in foods are necessary. In the present study, transcriptomics of L. monocytogenes grown in the presence of essential oil extracted from Baccharis psiadioides were studied by RNA sequencing and reverse transcription quantitative polymerase chain reaction (RT-qPCR) experiments. The results obtained indicate that essential oil of $B$. psiadioides has potential bacteriostatic activity at the concentration tested, affecting Listeria cells functioning and development. Responses of the microorganism included upregulation of stress genes and downregulation of virulence genes, such as actA, hly and prfA, indicating a decrease in virulence and in the capacity of the microorganism to cause infection. Thus, the results presented here allow us to conclude that $B$. psiadioides essential oil may be an alternative means of controlling microorganisms proliferating in foods.
\end{abstract}

Electronic supplementary material The online version of this article (doi:10.1007/s13213-017-1277-z) contains supplementary material, which is available to authorized users.

Jeverson Frazzon

jeverson.frazzon@ufrgs.br

1 Postgraduate Program in Food Science and Technology, Food Science and Technology Institute (ICTA), Federal University of Rio Grande do Sul (UFRGS), Bento Gonçalves Ave. 9500 / Building, 43212 Porto Alegre, Rio Grande do Sul (RS), Brazil

2 Postgraduate Program in Cellular and Molecular Biology, Biotechnology Center (CBiot), Federal University of Rio Grande do Sul (UFRGS), Bento Gonçalves Ave. 9500 / Building, Porto Alegre, RS 43431, Brazil
Keywords Bacteriostasis $\cdot$ Essential oil $\cdot$ Listeria monocytogenes $\cdot$ Virulence $\cdot$ RNA sequencing $\cdot$ RT-qPCR

\section{Introduction}

Among studies involving food safety, Listeria monocytogenes stands out because of its high pathogenicity, mainly related to immunocompromised individuals, such as the elderly and neonates, and the high risk of its transplacental transmission in pregnant women (Allerberger and Wagner 2010; Girard et al. 2014). The microorganism has the ability to survive and proliferate at refrigeration temperatures, which is a major problem related to food production that extensively uses the cold chain in the processing and storage of products (Farber and Peterkin 1991). Moreover, increased transcription of several L. monocytogenes genes involved in virulence and stress

3 Institute for Research in Bioenergy, São Paulo State University (UNESP), 10th St. 2527, Rio Claro, São Paulo (SP), Brazil

4 Postgraduate Program in Genetics and Molecular Biology, Federal University of Rio Grande do Sul (UFRGS), Bento Gonçalves Ave. 9500 / Building 43323M, Porto Alegre, RS, Brazil

5 Department of Botany, Biosciences Institute, Federal University of Rio Grande do Sul (UFRGS), Bento Gonçalves Ave. 9500 / Building, 43433 Porto Alegre, RS, Brazil

6 Department of Microbiology, Immunology and Parasitology, Basic Health Sciences Institute (ICBS), Federal University of Rio Grande do Sul (UFRGS), Sarmento Leite St, Porto Alegre, RS 500, Brazil 
responses has already been demonstrated at $7{ }^{\circ} \mathrm{C}$ compared to $37^{\circ} \mathrm{C}$ (Pieta et al. 2014). Among the 13 described serotypes of L. monocytogenes, $1 / 2 \mathrm{a}, 1 / 2 \mathrm{~b}$ and $4 \mathrm{~b}$ are responsible for $95 \%$ of human infections, called listeriosis (Montero et al. 2015). Historically, serotype $4 \mathrm{~b}$ has caused the greatest proportion of listeriosis outbreaks and the largest number of cases per outbreak in the United States (Cartwright et al. 2013).

Essential oils (EO) are secondary metabolites produced by several plants, and can function as antimicrobials, antivirals, antimycotics, antipsoriatics, insecticides and in cancer treatments (Cowan 1999; Edris 2007; Reichling et al. 2009). The EO present in the Asteraceae plant family, with emphasis on Baccharis psiadioides (Less.) Joch. Müller (= Heterothalamus psiadioides Less.) (Giuliano and Freire 2011), has important anti-inflammatory properties (Fabri et al. 2011) and the ability to inhibit the growth of antibiotic resistant microorganisms, also reducing biofilm formation in abiotic surfaces (Negreiros et al. 2016). Natural compounds present in the essential oil of $B$. psiadioides $(\mathrm{EO} B p)$ are classified as terpenes, and can be divided into two fractions: (1) monoterpenes with a significant percentage composed of $\beta$-pinene; and (2) sesquiterpenes with Ar-curcumene as the major component.

Transcriptomic, proteomic, genetic and physiological analyses can identify L. monocytogenes molecular stress adaptation responses, by global expression changes in a large number of the cellular components (Soni et al. 2011). In addition to EO, nisin - a bacteriocin produced by several lactic acid bacteria (Delves-Broughton 1990) — presents antimicrobial potential against food pathogens. Proteomic analyses of $L$. monocytogenes cells treated with a sub-lethal concentration of nisin displayed an overexpression of proteins related to oxidative stress and production of cell membrane lipids (Miyamoto et al. 2015). Experiments carried out with the Gram-positive pathogenic bacterium Staphylococcus aureus, showed transcriptional alterations induced by tea tree oil produced as a steam distillate of Melaleuca alternifolia, which has broad-spectrum antibacterial activity, including altered regulation of genes involved in heat shock and cell wall metabolism (Cuaron et al. 2013). Furthermore, the mechanism of biofilm inhibition and virulence attenuation in enterohemorrhagic Escherichia coli O157:H7 (EHEC) treated with eugenol and eugenol-rich oil was shown through transcriptional and phenotypic assays (Kim et al. 2016).

The use of natural compounds with antimicrobial potential represents an alternative means to combat pathogen growth; therefore, the present work aimed to analyze the differential transcriptome profile of $L$. monocytogenes grown in the presence of EOBp using RNA sequencing (RNA-Seq) and reverse transcription quantitative polymerase chain reaction (RT-qPCR).

\section{Materials and methods}

\section{Bacterial strain}

The L. monocytogenes 55 ( $L m 55)$ strain was isolated from cheese by the National Agricultural Laboratory of Rio Grande do Sul State (LANAGRO/RS) of the Ministry of Agriculture, Livestock and Food Supply (MAPA/Brazil), and serotyped at the Oswaldo Cruz Institute (State of Rio de Janeiro, RJ, Brazil) as serotype 1/2a (de Mello et al. 2008; Nes et al. 2010).

\section{Characterization of EO of $\boldsymbol{B}$. psiadioides}

EOBp was obtained from the Laboratory of Chemical Ecology and Chemotaxonomy [Department of Botany, Federal University of Rio Grande do Sul (UFRGS)]. Leaves of $B$. psiadiodes were collected from populations located in Porto Alegre, RS, and subjected to drying at room temperature, with subsequent extraction of EO in a modified Clevenger apparatus (Gottleib and Taveira-Magalhães 1960). $\mathrm{EO} B p$ was fractionated according to Kulisic et al. (2004) with some modifications, by column chromatography $(40 \mathrm{~cm}$ in length; $2 \mathrm{~cm}$ diameter) with silica ( $21 \mathrm{~g}, 63-200 \mu \mathrm{m}, 60^{\circ}$ pore; Sigma-Aldrich, St. Louis, MO), using pentane and diethyl ether to obtain fractions containing only non-polar and polar hydrocarbons, respectively. Fractions obtained were analyzed using gas chromatography-mass spectrometry (GC-MS). For the experiments, the whole extract (both fractions) was used in L. monocytogenes cultures.

\section{Experimental design, RNA sequencing and statistical analyses}

The $L m 55$ strain was cultivated in tryptone soy broth (TSB; HiMedia, Mumbai, Maharashtra, India) at $37^{\circ} \mathrm{C}$ under agitation. The MIC/2 of EOBp (Negreiros et al. 2016) was added in the exponential growth phase, when the microorganism had reached an optical density $\left(\mathrm{OD}_{600 \mathrm{~nm}}\right)$ between 0.3 and 0.4 , measured with an ultraviolet/visible spectrophotometer (Ultrospec 3100 Pro; Amersham Biosciences, Little Chalfont, UK). After $20 \mathrm{~min}$, growth was interrupted and cells were washed with $300 \mu \mathrm{L} 1 \mathrm{X}$ TE buffer $(10 \mathrm{mM}$ Tris-HCl $\mathrm{pH}$ 8.0, 1 mM EDTA pH 8.0; reagents from Sigma-Aldrich) and resuspended in $100 \mu \mathrm{L} 1 \mathrm{X}$ TE buffer. As control conditions, a parallel experiment was conducted without EOBp. Total RNA samples from $L m 55$ were isolated using the TRIzol ${ }^{\circledR}$ Reagent kit (Thermo Fisher Scientific, Waltham, MA), and spectrophotometer readings (ratio $\mathrm{OD}_{260 \mathrm{~nm}} / \mathrm{OD}_{280 \mathrm{~nm}}$ ) comprised values between 1.8 and 2.0 for all samples. Experiments were performed in biological triplicates and experimental quadruplicates. 
Total RNA samples were prepared using the TruSeq Stranded mRNA Sample Preparation-Low Sample (LS) protocol from the TruSeq Stranded mRNA Library Preparation Kit (Illumina, San Diego, CA), and a pool of libraries was prepared for subsequent sequencing according to the TruSeq Stranded mRNA Sample Preparation Guide (Illumina). Sequencing of the pooled libraries was performed on MiSeq Gene and Small Genome Sequencer equipment (Illumina) using the MiSeq Reagent kit v3 150 cycles (Illumina) according to the manufacturer's instructions. Finally, $600 \mu \mathrm{L}$ [570 $\mu \mathrm{L}$ of the pooled libraries and $30 \mu \mathrm{L}$ (5\%) of PhiX control solution] was added to the cartridge for subsequent sequencing.

The presence of adapters and quality of reads produced by RNA-Seq were determined for each library using FastQC software (http://www.bioinformatics.babraham.ac.uk/ projects/fastqc/). Based on these data, the Trim Galore! software (http://www.bioinformatics.babraham.ac.uk/ projects/trim_galore/) was used to eliminate sequences of reads with a quality below 30 , as well as the sequences of the Illumina adapters. The cleaned reads were then anchored with TopHat2 (Kim et al. 2013) to the reference genome of Lm55 (Pieta et al. 2015; deposited in GenBank under the accession no. LKHO00000000), and the fragments per kilobase million (FPKM) values for all genes were calculated using Cufflinks (Trapnell et al. 2012). The counting tables of the reads mapped to each gene were generated by the featureCounts module of Subread software (Liao et al. 2013) , for sequence alignment files generated by TopHat2. To perform statistical analyses for differential expression, the counting tables were analyzed in the R Bioconductor DESeq2 package v.1.12.3 (Love et al. 2014). For each treatment comparison, all genes with $\log _{2}$ foldchange greater than 1 and less than -1 were considered differentially expressed.. The protein sequences of these two groups of genes were functionally annotated with Blast2GO (Conesa et al. 2005), and the functional categories were visualized with the WEGO program (Ye et al. 2006). Sequences of the proteins were compared to the UniRef Enriched KEGG Orthology (UEKO) database (Guedes et al. 2011) using local BlastX (Altschul et al. 1997). The BlastX results were processed in the MySQL software (Oracle, Cupertino, CA), and the KEGG Orthology (KO) codes obtained were viewed on the iPATH2 web server (Yamada et al. 2011).

\section{Relative gene expression}

From total RNA, complementary DNA (cDNA) synthesis, recommended by Bustin et al. (2009), was performed according to Pieta et al. (2014), and relative gene expression was determined using RT-qPCR. Primers were using the GenScript tool (https://www.genscript.com/tools/real-timepcr-tagman-primer-design-tool) based on the genes that were differentially expressed and related to virulence, stress response and transcription factors of the microorganism. Genes chosen for analysis in the present study were actA, agrA, crp, degU, fri, fur, hly, iscR, malR, prfA, $\operatorname{sig} B$, and $\operatorname{sod}$ (Table 1 and Table $\mathrm{S} 1$ for functions of the coded proteins).

For RT-qPCR experiments, a solution containing 0.01$0.1 \mu \mathrm{M}$ of each primer; $25 \mu \mathrm{M}$ dNTPs (Promega, Madison, WI); $1 \mathrm{X}$ reaction buffer; $3 \mathrm{mM} \mathrm{MgCl}_{2}$; 1 X SYBR Green (BioRad, Hercules, CA); 0.25 U Platinum Taq DNA polymerase (Thermo Fisher Scientific); and ultrapure Milli-Q water to complete the final volume of $10 \mu \mathrm{L}$ was prepared. Standard curves were constructed with four points in twofold dilutions starting from a 1:50 cDNA concentration for each of the study primers to verify reaction efficiency in RT-qPCR experiments, determined with the StepOne v. 2.3 software based on slopes of plots and crossing points (Cps) versus log input of cDNA. For amplification, StepOnePlus ${ }^{\mathrm{TM}}$ Real Time-PCR System (Thermo Fisher Scientific) and 96-wells polystyrene microplates (Axygen Scientific, Union City, CA) were used. PCR was conducted at $94^{\circ} \mathrm{C}$ for $5 \mathrm{~min} ; 40$ cycles at $94^{\circ} \mathrm{C}$ for $15 \mathrm{~s}$, $60{ }^{\circ} \mathrm{C}$ for $10 \mathrm{~s}, 72{ }^{\circ} \mathrm{C}$ for $15 \mathrm{~s}$ and $60{ }^{\circ} \mathrm{C}$ for $35 \mathrm{~s}$; and a final melting curve between 50 and $99^{\circ} \mathrm{C}\left(\Delta 0.1{ }^{\circ} \mathrm{C} / \mathrm{s}\right)$. All experiments were performed in biological triplicates and experimental quadruplicates. The total volume present in each well was $20 \mu \mathrm{L}$, consisting of $10 \mu \mathrm{L}$ diluted cDNA (1:50) and $10 \mu \mathrm{L}$ reaction solution, and in the case of the negative control, a total volume consisting of $20 \mu \mathrm{L}$ reaction solution.

Housekeeping genes gap, rpoB and 16SrRNA (Table S2) were tested as candidates for RT-qPCR data normalization using the NormFinder algorithm (Andersen et al. 2004) and geNorm v. 3.5 software (Vandesompele et al. 2002). Relative expression of the genes was calculated using the $2^{-\Delta \Delta \mathrm{Ct}}$ method (Livak and Schmittgen 2001), considering the efficiency (E) of RT-qPCR reactions for each of the primers in the calculation of relative expression $\left(E^{-\Delta \Delta C t}\right)$, and statistical analyses were performed using one-way analysis of variance (ANOVA), at a significance level of 5\%, using Statistica software (Statsoft, Tulsa, OK). When there was a statistically significant difference $(P<0.05)$ between $C_{\mathrm{t}}$ (threshold cycle) values of the control and study conditions, the genes were considered to be more transcribed $\left(E^{-\Delta \Delta \mathrm{Ct}}>1\right)$ or less transcribed $\left(E^{\Delta \Delta \mathrm{Ct}}<1\right)$ during growth in the presence of $B p \mathrm{EO}$.

\section{Results and discussion}

\section{Determination of EOBp composition by GC-MS}

Total EOBp was used to perform our analysis and the $\mathrm{EO} B p$ fractions obtained were divided into two groups: one fraction was composed predominantly of monoterpenes and the other predominantly of sesquiterpenes. Results of GC-MS indicated the presence of a complex mixture of terpenes in the two 
Table 1 Sequences of primers used in the transcriptional analysis by RT-qPCR, with respective sizes of amplification fragments and annealing temperatures

\begin{tabular}{|c|c|c|c|}
\hline Gene & Nucleotide sequence & Amplicon size (bp) & Annealing temperature $\left({ }^{\circ} \mathrm{C}\right)$ \\
\hline \multirow[t]{2}{*}{ actA } & 5' AGAAATCATCCGGGAAACAG 3' & 147 & 58.98 \\
\hline & 5' CCTCTCCCGTTCAACTCTTC 3' & & 58.87 \\
\hline \multirow[t]{2}{*}{$\operatorname{agrA}$} & 5' CGGGTACTTGCCTGTATGAA 3' & 149 & 58.65 \\
\hline & 5' TGAATAGTTGGCGCTGTCTC 3' & & 59.03 \\
\hline \multirow[t]{2}{*}{ crp } & 5' ATTCACAGTTTGCGAATGCT 3' & 117 & 58.86 \\
\hline & 5' TTTGCAAATCAACATCACGA 3' & & 59.02 \\
\hline \multirow[t]{2}{*}{$\operatorname{deg} U$} & 5' GGCGCGTATATTCATCCAC 3' & 150 & 58.96 \\
\hline & 5' TACCTCGCACTCTCTATGCG 3' & & 59.20 \\
\hline \multirow[t]{2}{*}{ fri } & 5' GGCGAACAAATGGATGAAGT 3' & 108 & 59.94 \\
\hline & 5' ATAAGGCGCTTCTTCTACGC 3' & & 58.77 \\
\hline \multirow[t]{2}{*}{ fur } & 5' TTTAGCGCCTTCTTGTCTCA 3' & 114 & 58.80 \\
\hline & 5' GGCCTTGCAACCGTTTATAG 3' & & 59.61 \\
\hline \multirow[t]{2}{*}{ hly } & 5' AGCTCATTTCACATCGTCCA 3' & 124 & 59.24 \\
\hline & 5' TGGTAAGTTCCGGTCATCAA 3' & & 58.97 \\
\hline \multirow[t]{2}{*}{$i s c R$} & 5' ATCGGACCTCTTCGTAATGC 3' & 106 & 59.15 \\
\hline & 5' CGTATGATATCACCCGCAGT 3' & & 58.48 \\
\hline \multirow[t]{2}{*}{ malR } & 5' GAATCGTCTGGACCGGTAAT 3' & 110 & 58.86 \\
\hline & 5' AACGTGAGCCAAGTCCTTCT 3' & & 58.94 \\
\hline \multirow[t]{2}{*}{ prfa } & 5' GGAAGCTTGGCTCTATTTGC 3' & 145 & 59.07 \\
\hline & 5' ACAGCTGAGCTATGTGCGAT 3' & & 58.65 \\
\hline \multirow[t]{2}{*}{$\operatorname{sig} B$} & 5' TGGTGTCACGGAAGAAGAAG 3' & 135 & 58.85 \\
\hline & 5' TCCGTACCACCAACAACATC 3' & & 59.27 \\
\hline \multirow[t]{2}{*}{ sod } & 5' CCACCATTTGGGCTAAGAAT 3' & 94 & 58.90 \\
\hline & 5' GCGTTCCTGAAGATATTCGC 3' & & 59.81 \\
\hline
\end{tabular}

fractions. The fraction composed predominantly of monoterpenes revealed the presence of 20 compounds (Table 2); monoterpenes represented $71.82 \%$ of this fraction, with $\beta$ pinene as the major compound (43.81\%). Other compounds present in significant amounts were $\delta$-3-carene $(14.92 \%)$ and limonene $(10.82 \%)$ - both monoterpenes. In relation to the fraction composed predominantly by sesquiterpenes, the presence of 14 compounds was verified (Table 3), where the sesquiterpenes represented $93.59 \%$ of this fraction, Arcurcumene being the major compound $(40.12 \%)$. In this fraction, other compounds were also found in significant concentrations, such as bicyclogermacrene (15.89\%) and $\gamma$ muurolene $(15.68 \%$ )—both sesquiterpenes.

\section{Transcriptomic analysis}

In total, 333 genes presented a $\log _{2}$ foldchange $>-1$ ( -2 fold change cut off), being considered downregulated in the T4 sample (untreated with EOBp), and, consequently, upregulated in the O6 sample (treated with MIC/2 EOBp); and 273 genes presented a $\log _{2}$ foldchange $>1$ ( 2 fold change cut off), which means they were upregulated in the T4 and downregulated in the $\mathrm{O} 6$ samples (Table S3).
Based on these data, functional categories were visualized with the WEGO program, and the results regarding the effect of $\mathrm{EOBp}$ on differential genes expression in $L m 55$ strain are shown in Fig. 1 and Table 4 for the three categories listed: Biological Process (BP), Cellular Component (CC) and Molecular Function (MF).

With regard to the BP group (Fig. 1a), several processes presented a greater number of upregulated genes, such as biological regulation; cell cycle; catabolic process; amino acid and nitrogen compound, carbohydrate, cofactor, lipid, organic acid and sulfur metabolism; and response to stress. According to Bich et al. (2016), "biological regulation is what allows an organism to handle the effects of a perturbation, modulating its own constitutive dynamics in response to particular changes in internal and external conditions". As the results showed 12 upregulated genes and 4 downregulated genes in this category, indicating that $\mathrm{EO} B p$ can affect homeostasis causing changes in L. monocytogenes cells function and development. In support of this statement, growth in the presence of EOBp upregulated 22 genes and downregulated 5 genes related to stress response. In addition, several genes related to cofactor and sulfur metabolism were upregulated, and it should be noted that the iron-sulfur ([Fe-S]) clusters or cofactors (widely distributed in nature) are of great importance in several biological processes (Johnson et al. 2005). 
Table 2 Chemical composition of Baccharis psiadioides essential oil $(\mathrm{EO} B p$ ) fraction composed predominantly by monoterpenes. The relative percentage of each component was obtained directly from the peak areas of the chromatogram, considering $100 \%$ the sum of all evaluated peaks

\begin{tabular}{|c|c|c|c|}
\hline Component & $\mathrm{IK} \mathrm{cal}^{\mathrm{a}}$ & $\mathrm{IK} t \mathrm{tab}^{\mathrm{b}}$ & Yield $(\%)$ \\
\hline \multicolumn{4}{|l|}{ Monoterpenes } \\
\hline$\alpha$-pinene & 930 & 939 & 0.59 \\
\hline$\beta$-pinene & 978 & 979 & 43.81 \\
\hline Mircene & 993 & 990 & 0.93 \\
\hline$\delta$-3-carene & 1012 & 1011 & 14.92 \\
\hline p-cymene & 1024 & 1024 & 0.75 \\
\hline Limonene & 1029 & 1029 & 10.82 \\
\hline Total & & & 71.82 \\
\hline \multicolumn{4}{|l|}{ Sesquiterpenes } \\
\hline$\beta$-elemene & 1383 & 1390 & 1.65 \\
\hline$\beta$-caryophyllene & 1407 & 1419 & 1.15 \\
\hline Aromadendrene & 1426 & 1441 & 1.80 \\
\hline Dehydro-aromadendrene & 1434 & 1462 & 2.36 \\
\hline Allo-aromadendrene & 1446 & 1460 & 3.34 \\
\hline$\gamma$-gurjunene & 1457 & 1477 & 1.06 \\
\hline$\gamma$-muurolene & 1462 & 1479 & 1.09 \\
\hline Germacrene D & 1466 & 1481 & 0.80 \\
\hline Ar-curcumene $+\beta$-selinene & 1470 & $1480 / 1490$ & 5.32 \\
\hline Valencene & 1473 & 1496 & 0.87 \\
\hline$\alpha$-selinene & 1480 & 1498 & 4.28 \\
\hline$\alpha$-muurolene & 1485 & 1500 & 0.90 \\
\hline$\gamma$-cadinene & 1496 & 1513 & 1.53 \\
\hline$\delta$-cadinene & 1506 & 1523 & 2.03 \\
\hline Total & & & 28.18 \\
\hline
\end{tabular}

${ }^{\mathrm{a}}$ Calculated Kováts retention index

${ }^{\mathrm{b}}$ Tabulated Kováts retention index

Carbohydrate and lipid metabolism indicate energy generation, and may be considered catabolic processes, which refer to the assimilation or processing of organic compounds to obtain energy. Positive regulation of genes involved in the metabolism of several compounds may be related to the EO composition, since EO are complex mixtures of volatile substances, usually lipophilic, whose components include terpene hydrocarbons, simple alcohols, aldehydes, ketones, phenols, esters and fixed organic acids (Simões and Spitzer 1999). Araújo et al. (2016) analyzed the effects of argentilactone, a constituent of the EO from Hyptis ovalifolia, on the transcriptional profile, cell wall and oxidative stress of Paracoccidioides spp., a dimorphic pathogenic fungus. Their results demonstrated that the upregulated genes were related to metabolism; cell rescue, defense and virulence; energy and cell cycle; and DNA processing. The downregulated genes were related to metabolism, transcription, protein fate, and cell cycling and DNA processing.
Table 3 Chemical composition of EOBp fraction composed predominantly by sesquiterpenes. The relative percentage of each component was obtained directly from the peak areas of the chromatogram, considering $100 \%$ the sum of all evaluated peaks

\begin{tabular}{lrcr}
\hline Component & $\mathrm{IK} \mathrm{cal}^{\mathrm{a}}$ & $\mathrm{IK} \mathrm{tab}^{\mathrm{b}}$ & Yield (\%) \\
\hline $\begin{array}{l}\text { Monoterpenes } \\
\beta \text {-pinene }\end{array}$ & 973 & 979 & 1.41 \\
p-cymene & 1023 & 1024 & 0.64 \\
Limonene & 1027 & 1029 & 3.14 \\
(E)- $\beta$-ocimene & 1047 & 1050 & 1.22 \\
Total & & & 6.41 \\
Sesquiterpenes & & & \\
$\beta$-elemene & 1383 & 1390 & 4.30 \\
$\beta$-caryophyllene & 1407 & 1419 & 1.12 \\
$\alpha$-humulene & 1440 & 1454 & 6.56 \\
Allo-aromadendrene & 1446 & 1460 & 4.91 \\
$\gamma$-muurolene & 1468 & 1479 & 15.68 \\
Ar-curcumene & 1477 & 1480 & 40.12 \\
Bicyclogermacrene & 1485 & 1500 & 15.89 \\
Germacrene A & 1491 & 1509 & 2.07 \\
$\gamma$-cadinene & 1498 & 1513 & 1.30 \\
$\delta$-cadinene & 1508 & 1523 & 1.64 \\
Total & & & 93.59 \\
\hline
\end{tabular}

${ }^{a}$ Calculated Kováts retention index

${ }^{\mathrm{b}}$ Tabulated Kováts retention index

A larger number of downregulated genes related to BP were identified for categories such as biopolymers, macromolecules and protein metabolism; cell division; gene expression; ribosome biogenesis; and transmembrane transport. Biopolymer metabolism includes proteins, DNA and RNA production, and its downregulation may consequently affect ribosome biogenesis (32 downregulated versus two upregulated genes) and gene expression (34 downregulated versus four upregulated genes). The antimicrobial effect of EO may be responsible for downregulation of genes related to cell division, indicating the difficulty that the microorganism has, in the presence of the EO, to complete its binary fission and increase the microbial population.

All the categories related to $\mathrm{CC}$ (Fig. 1b) presented a larger number of downregulated genes, except for the external encapsulating structure. Some of those belonging to MF (Fig. 1c), such as structural constituent of ribosomes, translation regulators and transmembrane transporters, were also mostly downregulated. These data suggest an inverse correlation with the results for higher numbers of downregulated genes involved in $\mathrm{BP}$, such as ribosome biogenesis, biopolymer (DNA, RNA, proteins) production, and transmembrane transport. 
a)

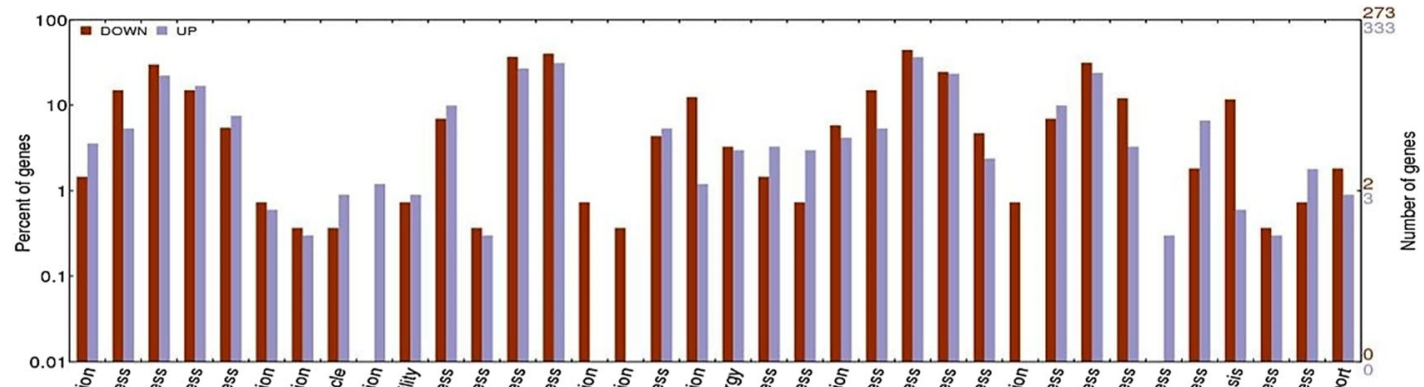

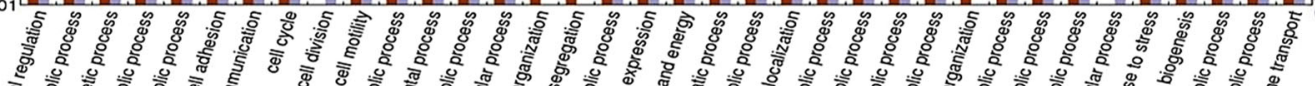

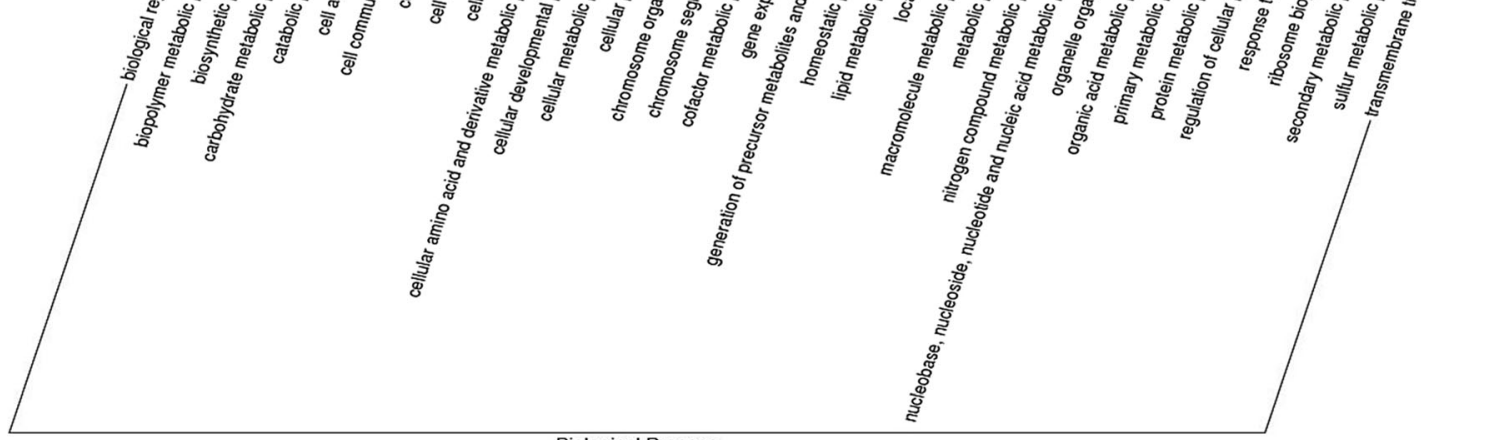

b)

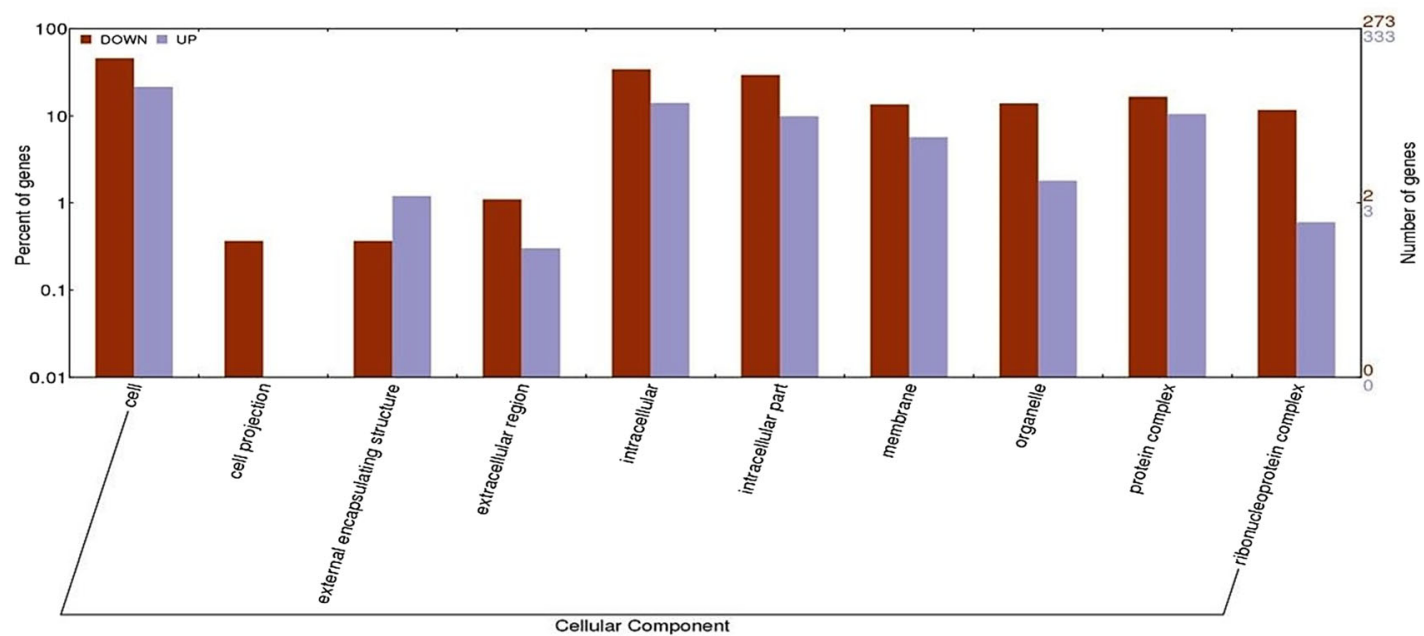

c)

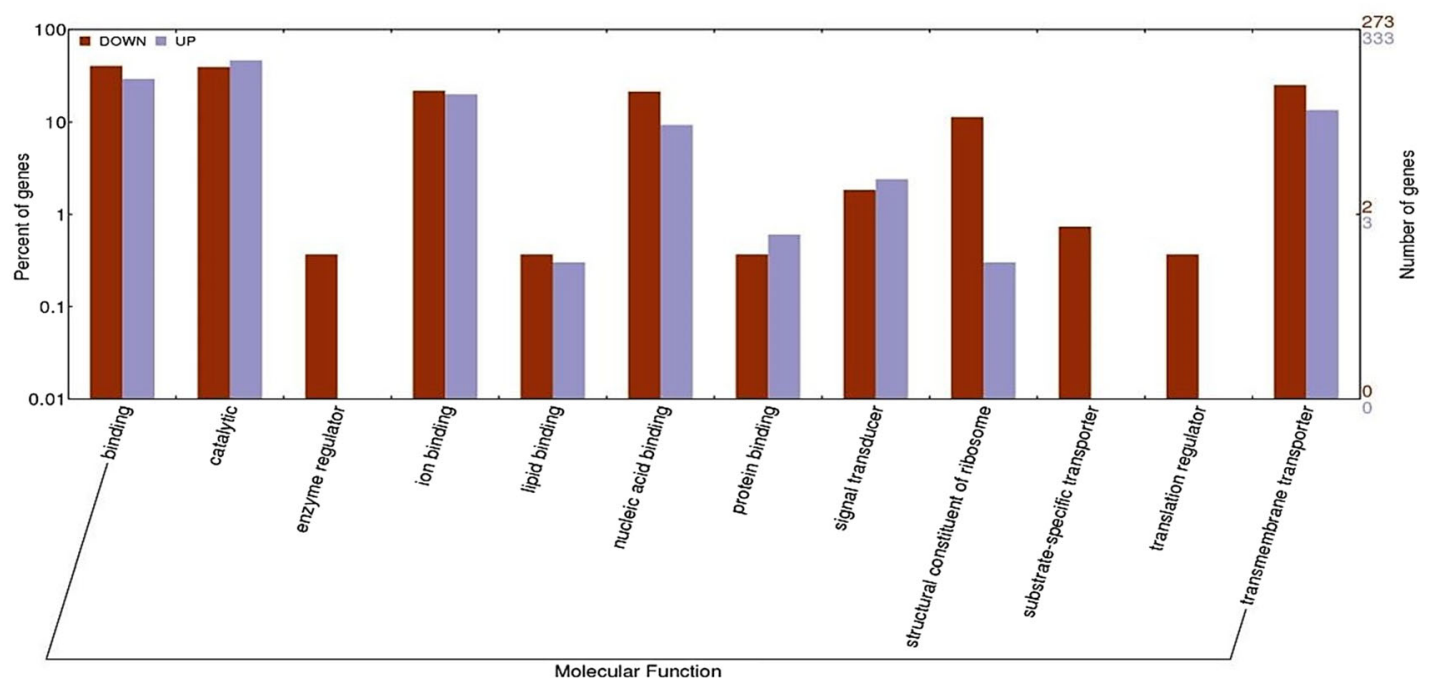


Fig. 1a-c Transcriptomic analysis results. Differential expression of genes related to functional categories a biological process (BP), b cellular component (CC), and $\mathbf{c}$ molecular function (MF) of Listeria monocytogenes 55 grown in the presence of Baccharis psiadioides essential oil $(\mathrm{EO} B p)$. Graphical representation generated using the WEGO program

\section{Transcriptional analysis of virulence genes and stress response genes}

First, to determine the reliability of the amplification data, the efficiency of the study primers was determined (Table S4), and the housekeeping genes gap, rpoB and $16 \operatorname{SrRNA}$ were tested as candidates for RT-qPCR data normalization using the NormFinder algorithm and geNorm v. 3.5 software. Both programs indicated $r p o B$ and $16 \operatorname{SrRNA}$ as the most stable genes and recommendable for data analysis, while gap was demonstrated as the least stable gene (Fig. S1 and Table S5). Results of relative gene expression for $L m 55$ strain cultivated in the presence of EOBp are shown in Fig. 2. The data shown here concur with the differential expression obtained with RNA-Seq, which allowed us to validate our experiments (Table S6).

Downregulation $(P<0.05)$ was observed in virulence genes, such as prfA, fur, hly, actA and agrA, in the presence of EOBp. Previous research has already demonstrated the antimicrobial and antibiofilm potential of plant-extracted EO against several food-borne pathogens, such as $S$. aureus, E. coli and L. monocytogenes (Upadhyay et al. 2013; LopezRomero et al. 2015) and the relation between the EO concentration and its bactericidal and/or bacteriostatic effect against these bacteria (Burt 2004; Mazzarrino et al. 2015). In addition, the extracted of $\mathrm{EOBp}$ showed a high concentration of $\beta$-pinene - a monoterpene that has been reported as one of the main chemicals responsible for the antimicrobial activity of several EOs.

Both PrfA and Fur are regulators involved in L. monocytogenes virulence and pathogenicity. PrfA controls the transcription of several virulence genes involved in the infection process, such as actA, which is responsible for the polymerization of actin tails, which propels the microorganism to neighboring cells, and the hly gene that codifies listeriolysin O (LLO), which is critical to survival of the microorganism in the phagocytes during the infection process (Xayarath and Freitag 2012). Thus, the significantly reduced transcription of $p r f A$ corroborates the reduced transcription of the hly gene. The agr system of $S$. aureus, widely conserved among Gram-positive bacteria, is involved in biofilm formation (Lyon and Novick 2004), and the AgrA-AgrC two-component system has been studied extensively because of its control of virulence factors (Novick 2000). In L. monocytogenes, as in $S$. aureus, $\operatorname{agr} B, \operatorname{agrD}, \operatorname{agr} C$ and $\operatorname{agr} A$ genes are organized in a unique operon, regulating microorganism adhesion to surfaces, fundamental for a proper biofilm formation, in addition to its involvement in the Listeria infection process in mammals (Riedel et al. 2009). An earlier in vivo study showed that the virulence of a $\Delta a g r A$ L. monocytogenes strain was attenuated, demonstrating the role of the agr locus in the virulence of this microorganism, and its influence in the production of several secreted proteins, such as LLO (Autret et al. 2003).

Iron, an abundant element in nature, acts as a cofactor for several enzymes involved in microorganism metabolism, being required by almost all bacteria. However, iron concentrations above physiological levels can be toxic for microorganisms. A regulator of ferric iron uptake in many bacteria, Fur is involved with L. monocytogenes virulence and survival in the host (Rea et al. 2004). Mutations in the fur gene reduced microorganism pathogenicity in mice, indicating that disruption of intracellular iron homeostasis contributes to a lower ability of this pathogen to successfully establish infection (Newton et al. 2005; Olsen et al. 2005). In agreement with this, McLaughlin et al. (2012) demonstrated that deregulation of iron uptake through the elimination of Fur significantly impacts upon virulence potential in several pathogenic bacteria, including L. monocytogenes, as mutants in Fur-regulated loci resulted in a significant reduction in virulence potential relative to the wild-type. A recent study characterized the composition of an EO extracted from the leaf of Rhaphiodon echinus GC-MS experiments revealed the presence of monoterpenes, sesquiterpenes, and the metal chelation potential of this oil (Duarte et al. 2016). As the EOBp constitutes by both monoterpenes and sesquiterpenes, this may explain the significantly decreased transcription of fur, which is downregulated under iron-limited conditions (Ledala et al. 2010).

While some genes associated with virulence were downregulated, genes correlated with stress response such as $\operatorname{deg} U$, $\operatorname{sig} B, \operatorname{crp}$, fri, iscR, sod and malR were upregulated in the presence of $\mathrm{EO} B p$. An upregulation gene example was a stress response transcription factor named sigma $\mathrm{B}\left(\sigma^{\mathrm{B}}\right)$, which contributes to the microorganism's resistance to several conditions unsuitable to its development, such as acidic, osmotic and energy stresses (O’Byrne and Karatzas 2008).

$\mathrm{DegU}$ is a regulator of the expression of flagellar and chemotaxis genes in L. monocytogenes, involved in microorganism motility but not required for its virulence (Williams et al. 2005). Burke et al. (2014) demonstrated that L. monocytogenes uses different enzymes and regulators of gene expression, such as DegU, to resist the bactericidal activity of lysozymes, which degrade the bacterial cell wall, resulting in bacteriolysis. In addition, they suggested that $\mathrm{DegU}$ is one of the major regulators of lysozyme resistance in L. monocytogenes, a mechanism commonly found in other pathogens. Members of the Crp/Fnr transcription factor family have several related functions in microorganisms, such as regulation of virulence, metabolic pathways and stress response. 
Table 4 Number of down and upregulated genes related to processes belonging to the functional categories studied [Biological Process (BP); Cellular Component (CC); Molecular Function MF)] in Listeria monocytogenes 55 grown in the presence of $\mathrm{EO} B p$

\begin{tabular}{|c|c|c|}
\hline & Down & Up \\
\hline \multicolumn{3}{|l|}{$\mathrm{BP}$} \\
\hline Biological regulation & 4 & 12 \\
\hline Biopolymer metabolic process & 41 & 18 \\
\hline Biosynthetic process & 82 & 74 \\
\hline Carbohydrate metabolic process & 41 & 56 \\
\hline Catabolic process & 15 & 25 \\
\hline Cell adhesion & 2 & 2 \\
\hline Cell communication & 1 & 1 \\
\hline Cell cycle & 0 & 4 \\
\hline Cell division & 45 & 35 \\
\hline Cell motility & 2 & 3 \\
\hline Cellular amino acid and derivative metabolic process & 19 & 33 \\
\hline Cellular developmental process & 1 & 1 \\
\hline Cellular metabolic process & 101 & 90 \\
\hline Cellular process & 110 & 104 \\
\hline Chromosome organization & 2 & 0 \\
\hline Chromosome segregation & 1 & 0 \\
\hline Cofactor metabolic process & 12 & 18 \\
\hline Gene expression & 34 & 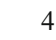 \\
\hline Generation of precursor metabolites and energy & 9 & 10 \\
\hline Homeostatic process & 4 & 11 \\
\hline Lipid metabolic process & 2 & 10 \\
\hline Localization & 16 & 14 \\
\hline Macromolecule metabolic process & 41 & 18 \\
\hline Metabolic process & 122 & 122 \\
\hline Nitrogen compound metabolic process & 67 & 78 \\
\hline Nucleobase, nucleoside, nucleotide and nucleic acid metabolic process & 13 & \\
\hline Organelle organization & 2 & 0 \\
\hline Organic acid metabolic process & 19 & 33 \\
\hline Primary metabolic process & 86 & 80 \\
\hline Protein metabolic process & 33 & 11 \\
\hline Regulation of cellular process & 0 & 1 \\
\hline Response to stress & 5 & 22 \\
\hline Ribosome biogenesis & 32 & 2 \\
\hline Secondary metabolic process & 1 & \\
\hline Sulfur metabolic process & 2 & \\
\hline Transmembrane transport & 5 & \\
\hline \multicolumn{3}{|l|}{ Cellular component } \\
\hline Cell & 124 & 71 \\
\hline Cell projection & 1 & 0 \\
\hline External encapsulating structure & 1 & 4 \\
\hline Extracellular region & 3 & 1 \\
\hline Intracellular & 93 & 47 \\
\hline Intracellular part & 80 & 33 \\
\hline Membrane & 37 & 19 \\
\hline Organelle & 38 & 6 \\
\hline Protein complex & 45 & 35 \\
\hline Ribonucleoprotein complex & 32 & 2 \\
\hline \multicolumn{3}{|l|}{ Molecular function } \\
\hline Binding & 110 & 97 \\
\hline Catalytic & 107 & 154 \\
\hline Enzyme regulator & 1 & 0 \\
\hline Ion binding & 59 & 66 \\
\hline Lipid binding & 1 & 1 \\
\hline Nucleic acid binding & 58 & 31 \\
\hline Protein binding & 1 & 2 \\
\hline Signal transducer & 5 & \\
\hline Structural constituent of ribossome & 31 & \\
\hline Substrate-specific transporter & 2 & 0 \\
\hline Translation regulator & 1 & 0 \\
\hline Transmembrane transporter & 68 & 45 \\
\hline
\end{tabular}

as well as toxin production or pilus synthesis (Körner et al. 2003). In addition, the Crp family of transcription factors is 
Fig. 2 Transcriptional analysis results. Relative expression of actA, agrA, crp, $\operatorname{deg} U$, fri, fur, hly, iscR, malR, prfA, $\operatorname{sig} B$ and $\operatorname{sod}$, normalized with $r$ roB and 16SrRNA, for Listeria monocytogenes 55 grown in the presence of $\mathrm{EO} B p$, and respective bars indicating the standard deviation values. All genes were statistically less or more transcribed $(P<0.05)$; graphical representation obtained with Microsoft Office Excel 2007

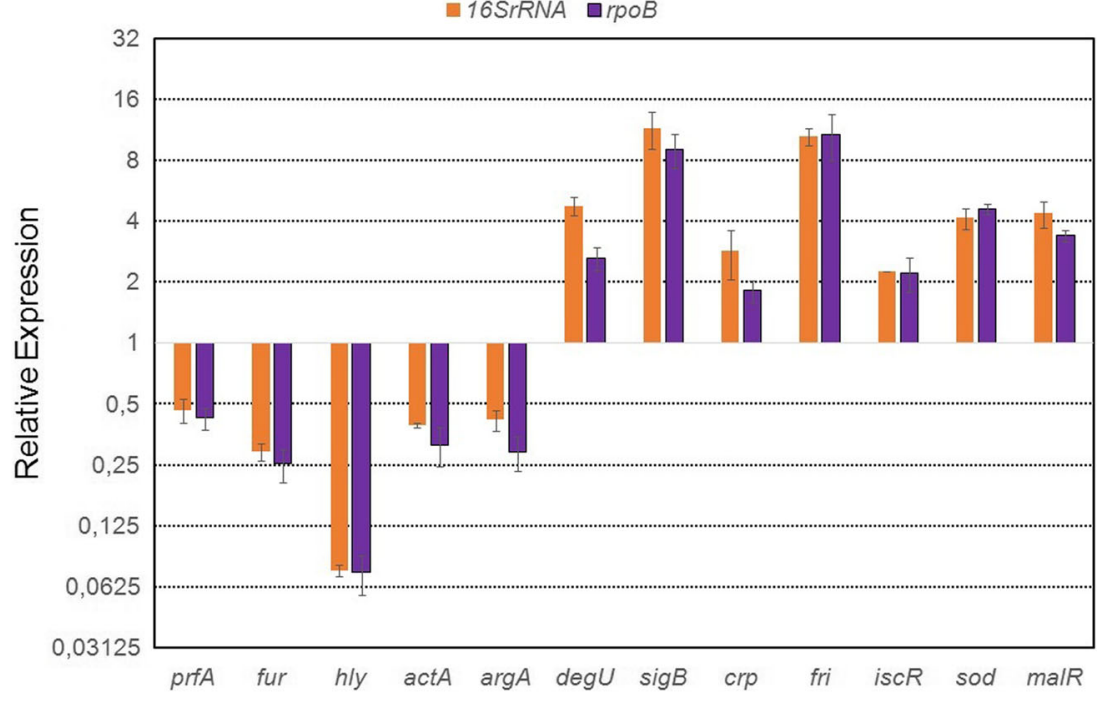

involved in various metabolic pathways in bacteria, acting in response to environmental changes. It has been shown that Crp acts as a transcription regulator in response to stresses in Deinococcus radiodurans (Yang et al. 2016). This Grampositive bacterium is characterized by its efficient DNA repair ability and extreme stress resistance (Makarova et al. 2001) and generally considered to be an ideal model organism for studying bacterial resistance mechanisms under various stress conditions. This recent study demonstrated that the transcription levels of crp genes were increased to different extents when the bacteria were exposed to oxidizing agents. The Crp mutants were more susceptible to hydrogen peroxide $\left(\mathrm{H}_{2} \mathrm{O}_{2}\right)$ than the wild-type strain, proving the important role of these proteins in stress resistance of $D$. radiodurans.

The fri gene encodes an iron-binding ferritin-like protein (Fri) that belongs to the Dps (DNA-binding proteins from starved cells) family of proteins (Haikarainen and Papageorgiou 2010). Ferritin is the most important iron reserve protein, found in all cells, especially in those involved in ferric compound synthesis, iron reserves and metabolism, which is required by several bacteria. It has been shown that the fri gene is repressed by Fur (Fiorini et al. 2008), being upregulated under several conditions, such as iron restriction, heat and cold shock (Hébraud and Guzzo 2000). The results obtained in the present study confirm this, since the fur gene was downregulated, and, consequently, the fri gene was upregulated in the presence of $\mathrm{EO} B p$. A recent study demonstrated that the cell-envelope stress response in L. monocytogenes is linked to the osmotic stress response, confirming the results obtained in the present work, because active terpenes compounds present in $\mathrm{EOBp}$ act by binding the cell membrane of microorganisms (Milecka et al. 2015). Several studies suggest that Fri has a global impact on the L. monocytogenes regulatory network (Dussurget et al. 2005; Olsen et al. 2005 ), and this protein is also a mediator of beta-lactam tolerance and resistance to antibiotics such as cephalosporins (Krawczyk-Balska et al. 2012).

Iron is also necessary for cellular growth, development and survival, thus the [Fe-S] clusters - isc-are cofactors of enzymes involved in several biological processes related to respiration, DNA repair, carbon/nitrogen metabolism and regulation of gene expression (Py and Barras 2010). The isc operon encodes IscR, a [2Fe-2S] transcription factor that is involved in $[\mathrm{Fe}-\mathrm{S}]$ cluster biogenesis, being a regulator responsible for governing various physiological processes during growth and stress responses (Mettert and Kiley 2014). IscR is widely conserved among proteobacteria (Rodionov et al. 2006); however, in Gram-positive bacteria, it is not well characterized. A relevant study performed by Santos et al. (2014) demonstrated that a gene from the unique Gram-positive dissimilatory metal-reducing bacterium Thermincola potens, which belongs to the Firmicutes phylum, the same as Listeria species, encodes a functional IscR homolog that is likely involved in the regulation of iron-sulfur cluster biogenesis.

Catalase (Kat) and superoxide dismutase (Sod) are the two major proteins implicated in protection against superoxides and reactive oxygen species (ROS) (Camejo et al. 2009), as the sod gene acts by dismutating the superoxide radical anion $\mathrm{O}_{2}{ }^{*}$ - to $\mathrm{H}_{2} \mathrm{O}_{2}$, which is transformed into $\mathrm{H}_{2} \mathrm{O}$ by the kat gene (Imlay 2003). Sod proteins can be classified into different types according to their metal cofactors, but only manganese-dependent superoxide dismutase (MnSod) is found in L. monocytogenes (Vasconcelos and Deneer 1994). In the present study, the sod gene was upregulated in the presence of $\mathrm{EOBp}$, in agreement with others studies related to the oxidative stress response. In addition to providing bacterial resistance against host-generated toxic oxygen species, sod gene induction has also been demonstrated during biofilm formation (Trémoulet et al. 2002), which is related to 
oxidative stress in several bacteria as a response to changes in environmental conditions (Arce Miranda et al. 2011; Bitoun et al. 2011). As well as EO, ozone also has antimicrobial potential, being widely used in food processing due to its significant disinfection and ability to degrade rapidly. Both catalase and superoxide dismutase were found to protect pathogenic L. monocytogenes cells from ozone attack (Fisher et al. 2000).

Listeria species are widespread in the environment and soils, which are rich in complex carbohydrates like starch and its degradation products maltodextrins and maltose, requiring efficient uptake mechanisms for these compounds (Gopal et al. 2010). The maltose repressor protein (MalR) is a member of the LacI/GalR regulatory family, which is responsible for controlling a broad range of bacterial metabolic processes, from selective carbon source utilization to nucleotide synthesis and amino acid catabolism (Nguyen and Saier 1995; Swint-Kruse and Matthews 2009).

In conclusion, the use of natural compounds provides a new way for the scientific community to control the growth of microorganisms in food products. Results obtained in the present study on the antimicrobial effect of EOBp on Lm55 isolated from dairy products (cheese), indicate a downregulation of virulence genes and upregulation of stress response genes, which results in destabilization of bacteria. L. monocytogenes is considered one of the pathogens with higher mortality rates involved in foodborne outbreaks, thus the possibility of reducing its pathogenicity becomes of great relevance for future research.

Acknowledgements We acknowledge the National Council for Scientific and Technological Development of Brazil (CNPq) (J. F. Grants \#473181/2013-4 and \#303603/2015-1).

\section{Compliance with ethical standards}

Conflict of interest The authors declare that they have no conflict of interest.

\section{References}

Allerberger F, Wagner M (2010) Listeriosis: a resurgent foodborne infection. Clin Microbiol Infect 16:16-23

Altschul SF, Madden TL, Schäffer AA, Zhang J, Zhang Z, Miller W, Lipman DJ (1997) Gapped BLAST and PSI-BLAST: a new generation of protein database search programs. Nucleic Acids Res 25: 3389-3402

Andersen CL, Jensen JL, Ørntoft TF (2004) Normalization of real-time quantitative reverse transcription-PCR data: a model-based variance estimation approach to identify genes suited for normalization, applied to bladder and colon cancer data sets. Cancer Res 64:52455250

Araújo FS, Coelho LM, Silva LC, Neto BRS, Parente-Rocha JA, Bailão AM, de Oliveira CMA, Fernandes GR, Hernández O, Ochoa JGM, Soares CMA, Pereira M (2016) Effects of argentilactone on the transcriptional profile, cell wall and oxidative stress of Paracoccidioides spp. PLoS Negl Trop Dis. doi:10.1371/journal. pntd.0004309

Arce Miranda JE, Sotomayor CE, Albesa I, Paraje MG (2011) Oxidative and nitrosative stress in Staphylococcus aureus biofilm. FEMS Microbiol Lett 315:23-29

Autret N, Raynaud C, Dubail I, Berche P, Charbit A (2003) Identification of the agr locus of Listeria monocytogenes: role in bacterial virulence. Infect Immun 71:4463-4471

Bich L, Mossio M, Ruiz-Mirazo K, Moreno A (2016) Biological regulation: controlling the system from within. Biol Philos 31:237-265

Bitoun JP, Nguyen AH, Fan Y, Burne RA, Wen ZT (2011) Transcriptional repressor Rex is involved in regulation of oxidative stress response and biofilm formation by Streptococcus mutans. FEMS Microbiol Lett 320:110-117

Burke TP, Loukitcheva A, Zemansky J, Wheeler R, Boneca IG, Portnoya DA (2014) Listeria monocytogenes is resistant to lysozyme through the regulation, not the acquisition, of cell wall-modifying enzymes. $\mathrm{J}$ Bacteriol 196:3756-3767

Burt S (2004) Essential oils: their antibacterial properties and potential applications in foods - a review. Int J Food Microbiol 94:223-253

Bustin SA, Benes V, Garson JA, Hellemans J, Huggett J, Kubista M, Mueller R, Nolan T, Pfaffl MW, Shipley GL, Vandesompele J, Wittwer CT (2009) The MIQE guidelines: minimum information for publication of quantitative real-time PCR experiments. Clin Chem 55:611-622

Camejo A, Buchrieser C, Couve E, Carvalho F, Reis O, Ferreira P, Sousa S, Cossart P, Cabanes D (2009) In vivo transcriptional profiling of Listeria monocytogenes and mutagenesis identify new virulence factors involved in infection. PLoS Pathog 5:e1000449. doi:10. 1371/journal.ppat.1000449

Cartwright EJ, Jackson KA, Johnson SD, Graves LM, Silk BJ, Mahon BE (2013) Listeriosis outbreaks and associated food vehicles, United States, 1998-2008. Emerg Infect Dis 19:1-9. doi:10.3201/ eid1901.120393

Conesa A, Götz S, García-Gómez JM, Terol J, Talón M, Robles M (2005) Blast2GO: a universal tool for annotation, visualization and analysis in functional genomics research. Bioinformatics 21:3674-3676

Cowan MM (1999) Plant products as antimicrobial agents. Clin Microbiol Rev 12:564-582

Cuaron JA, Dulal S, Song Y, Singh AK, Montelongo CE, Yu W, Nagarajan V, Jayaswal RK, Wilkinson BJ, Gustafson JE (2013) Tea tree oil-induced transcriptional alterations in Staphylococcus aureus. Phytother Res 27:390-396

de Mello JF, Einsfeldt K, Frazzon APG, da Costa M, Frazzon J (2008) Molecular analysis of the iap gene of Listeria monocytogenes isolated from cheeses in Rio Grande do Sul, Brazil. Braz J Microbiol 39:169-172

Delves-Broughton J (1990) Nisin and its application as food preservative. J Soc Dairy Technol 43(3):73-77

Duarte AL, de Menezes IRA, Braga MFBM, Leite NF, Barros LM, Waczuk EP, da Silva MAP, Boligon A, Rocha JBT, Souza DO, Kamdem JP, Coutinho HDM, Burger ME (2016) Antimicrobial activity and modulatory effect of essential oil from the leaf of Rhaphiodon echinus (Nees \& Mart) Schauer on some antimicrobial drugs. Molecules 21:743. doi:10.3390/molecules21060743

Dussurget O, Dumas E, Archambaud C, Chafsey I, Chambon C, Hébraud M, Cossart P (2005) Listeria monocytogenes ferritin protects against multiple stresses and is required for virulence. FEMS Microbiol Lett $250: 253-261$

Edris AE (2007) Pharmaceutical and therapeutic potentials of essential oils and their individual volatile constituents: a review. Phytother Res 21:308-323

Fabri RL, Nogueira MS, Dutra LB, Bouzada MLM, Scio E (2011) Potencial antioxidante e antimicrobiano de espécies da família Asteraceae. Rev Bras Plant Med 13:183-189 
Farber JM, Peterkin PI (1991) Listeria monocytogenes, a food-borne pathogen. Microbiol Rev 55:476-511

Fiorini F, Stefanini S, Valenti P, Chiancone E, de Biase D (2008) Transcription of the Listeria monocytogenes fri gene is growthphase dependent and is repressed directly by Fur, the ferric uptake regulator. Gene 410:113-121

Fisher CW, Lee D, Dodge BA, Hamman KM, Robbins JB, Martin SE (2000) Influence of catalase and superoxide dismutase on ozone inactivation of Listeria monocytogenes. Appl Environ Microbiol 66:1405-1409

Girard D, Leclerqc A, Laurent E, Lecuit M, de Valk H, Goulet V (2014) Pregnancy-related listeriosis in France, 1984 to 2011, with a focus on 606 cases from 1999 to 2011. Euro Surveill 19:pii: 20909. Available online: http://www.eurosurveillance.org/ViewArticle. aspx?ArticleId=20909

Giuliano DA, Freire SE (2011) Nuevas secciones en Baccharis (Asteraceae, Astereae) de America del Sur. Ann Mo Bot Gard 98: 331-347

Gopal S, Berg D, Hagen N, Schriefer EM, Stoll R, Goebel W, Kreft J (2010) Maltose and maltodextrin utilization by Listeria monocytogenes depend on an inducible $\mathrm{ABC}$ transporter which is repressed by glucose. PLoS One 5(4):e10349. doi:10.1371/journal. pone.0010349

Gottleib OR, Taveira-Magalhães M (1960) Modified distillation trap. Chem Anal 49:114-115

Guedes RLM, Prosdocimi F, Fernandes GR, Moura LK, Ribeiro HAL, Ortega JM (2011) Amino acids biosynthesis and nitrogen assimilation pathways: a great genomic deletion during eukaryotes evolution. BMC Genomics. doi:10.1186/1471-2164-12-S4-S2

Haikarainen T, Papageorgiou AC (2010) Dps-like proteins: structural and functional insights into a versatile protein family. Cell Mol Life Sci $67: 341-351$

Hébraud M, Guzzo J (2000) The main cold shock protein of Listeria monocytogenes belongs to the family of ferritin-like proteins. FEMS Microbiol Lett 190:29-34

Imlay JA (2003) Pathways of oxidative damage. Annu Rev Microbiol 57: 395-418

Johnson DC, Dean DR, Smith AD, Johnson MK (2005) Structure, function, and formation of biological iron-sulfur clusters. Annu Rev Biochem 74:247-281

Kim D, Pertea G, Trapnell C, Pimentel H, Kelley R, Salzberg SL (2013) TopHat2: accurate alignment of transcriptomes in the presence of insertions, deletions and gene fusions. Genome Biol 14:R36. doi:10. 1186/gb-2013-14-4-r36

Kim YG, Lee JH, Gwon G, Kim SI, Park JG, Lee J (2016) Essential oils and eugenols inhibit biofilm formation and the virulence of Escherichia coli O157:H7. Sci Rep 6:3637. doi:10.1038/srep36377

Körner H, Sofia HJ, Zumft WG (2003) Phylogeny of the bacterial superfamily of Crp-Fnr transcription regulators: exploiting the metabolic spectrum by controlling alternative gene programs. FEMS Microbiol Rev 27:559-592

Krawczyk-Balska A, Marchlewicz J, Dudek D, Wasiak K, Samluk A (2012) Identification of a ferritin-like protein of Listeria monocytogenesas a mediator of $\beta$-lactam tolerance and innate resistance to cephalosporins. BMC Microbiol 12:278. doi:10.1186/14712180-12-278

Kulisic T, Radonic A, Katalinic V, Milos M (2004) Use of different methods for testing antioxidative activity of orégano essential oil. Food Chem 85:633-640

Ledala N, Sengupta M, Muthaiyan A, Wilkinson BJ, Jayaswal RK (2010) Transcriptomic response of Listeria monocytogenes to iron limitation and Fur mutation. Appl Environ Microbiol 76:406-416

Liao Y, Smyth GK, Shi W (2013) The Subread aligner: fast, accurate and scalable read mapping by seed-and-vote. Nucleic Acids Res 41: e108-e108
Livak KJ, Schmittgen TD (2001) Analysis of relative gene expression data using real-time quantitative PCR and the 2(-Delta Delta C(T)) method. Methods 25:402-408

Lopez-Romero JC, González-Ríos H, Borges A, Simões M (2015) Antibacterial effects and mode of action of selected essential oils components against Escherichia coli and Staphylococcus aureus. Evid Based Complement Alternat Med 2015:795435. doi:10.1155/ 2015/795435

Love MI, Huber W, Anders S (2014) Moderated estimation of fold change and dispersion for RNA-seq data with DESeq2. Genome Biol 15(12):550. doi:10.1186/s13059-014-0550-8

Lyon GJ, Novick RP (2004) Peptide signaling in Staphylococcus aureus and other Gram-positive bacteria. Peptides 25:1389-1403

Makarova KS, Aravind L, Wolf YI, Tatusov RL, Minton KW, Koonin EV, Daly MJ (2001) Genome of the extremely radiation-resistant bacterium Deinococcus radiodurans viewed from the perspective of comparative genomics. Microbiol Mol Biol Rev 65:44-79

Mazzarrino G, Paparella A, Chaves-López C, Faberi A, Sergi M, Sigismondi C, Compagnone D, Serio A (2015) Salmonella enterica and Listeria monocytogenes inactivation dynamics after treatment with selected essential oils. Food Control 50:794-803

McLaughlin HP, Xiao Q, Rea RB, Pi H, Casey PG, Darby T, Charbit A, Sleator RD, Joyce SA, Cowart RE, Hill C, Klebba PE, Gahan CG (2012) A putative P-type ATPase required for virulence and resistance to haem toxicity in Listeria monocytogenes. PLoS One 7(2): e30928. doi:10.1371/journal.pone.0030928

Mettert EL, Kiley PJ (2014) Coordinate regulation of the Suf and Isc Fe-S cluster biogenesis pathways by IscR is essential for viability of Escherichia coli. J Bacteriol 196:4315-4323

Milecka D, Samluk A, Wasiak K, Krawczyk-Balska (2015) An essential role of a ferritin-like protein in acid stress tolerance of Listeria monocytogenes. Arch Microbiol 197:347-351

Montero D, Bodero M, Riveros G, Lapierre L, Gaggero A, Vidal RM, Vidal M (2015) Molecular epidemiology and genetic diversity of Listeria monocytogenes isolates from a wide variety of ready-toeat foods and their relationship to clinical strains from listeriosis outbreaks in Chile. Front Microbiol 6:384. doi:10.3389/fmicb. 2015.00384

Miyamoto KN, Monteiro KM, da Silva CK, Lorenzatto KR, Ferreira HB, Brandelli A (2015) Comparative proteomic analysis of Listeria monocytogenes ATCC 7644 exposed to a sublethal concentration of nisin. J Proteome 119:230-237. doi:10.1016/j.jprot.2015.02.006

Negreiros MO, Pawlowski A, Zini CA, Soares GLG, Motta AS, Frazzon APG (2016) Antimicrobial and Antibiofilm activity of Baccharis psiadioides essential oil against antibiotic-resistant Enterococcus faecalis strains. Pharm Biol 54:3272-3279

Nes FD, Riboldi GP, Frazzon APG, d'Azevedo PA, Frazzon J (2010) Antimicrobial resistance and investigation of the molecular epidemiology of Listeria monocytogenes in dairy products. Rev Soc Bras Med Trop 43:382-385

Newton SM, Klebba PE, Raynaud C, Shao Y, Jiang X, Dubail I, Archer C, Frehel C, Charbit A (2005) The svpA-srtB locus of Listeria monocytogenes: fur-mediated iron regulation and effect on virulence. Mol Microbiol 55:927-940

Nguyen CC, Saier MH (1995) Phylogenetic, structural and functional analyses of the LacI-GalR family of bacterial transcription factors. FEBS Lett 377:98-102

Novick RP (2000) Pathogenicity factors and their regulation. In: Fischetti VA, Novick RP, Ferreti JJ, Portnoy DA, Rood JI (eds) Grampositive pathogens. ASM, Washington, pp 392-407

O'Byrne CP, Karatzas KA (2008) The role of sigma B (sigma B) in the stress adaptations of Listeria monocytogenes: overlaps between stress adaptation and virulence. Adv Appl Microbiol 65:115-140

Olsen KN, Larsen MH, Gahan CG, Kallipolitis B, Wolf XA, Rea R, Hill C, Ingmer H (2005) The Dps-like protein Fri of Listeria 
monocytogenes promotes stress tolerance and intracellular multiplication in macrophage-like cells. Microbiology 151:925-933

Pieta L, Garcia FB, Riboldi GP, de Oliveira LA, Frazzon APG, Frazzon J (2014) Transcriptional analysis of genes related to biofilm formation, stress-response, and virulence in Listeria monocytogenes strains grown at different temperatures. Ann Microbiol 64:17071714

Pieta L, Campos FS, Mariot RF, Prichula J, de Moura TM, Frazzon APG, Frazzon J (2015) Complete genome sequences of two Listeria monocytogenes serovars, $1 / 2 \mathrm{a}$ and $4 \mathrm{~b}$, isolated from dairy products in Brazil. Genome Announc 3(6): e01494-15. doi:10.1128/ genomeA.01494-15

Py B, Barras F (2010) Building Fe-S proteins: bacterial strategies. Nat Rev Microbiol 8:436-446

Rea RB, Gahan CG, Hill C (2004) Disruption of putative regulatory loci in Listeria monocytogenes demonstrates a significant role for Fur and PerR in virulence. Infec Immun 72:717-727

Reichling J, Schnitzler P, Suschke U, Saller R (2009) Essential oils of aromatic plants with antibacterial, antifungal, antiviral, and cytotoxic properties - an overview. Forsch Komplementmed 16:79-90

Riedel CU, Monk IR, Casey PG, Waidmann MS, Gahan CG, Hill C (2009) AgrD-dependent quorum sensing affects biofilm formation, invasion, virulence and global gene expression profiles in Listeria monocytogenes. Mol Microbiol 71:1177-1189

Rodionov DA, Gelfand MS, Todd JD, Curson AR, Johnston AW (2006) Computational reconstruction of iron- and manganese-responsive transcriptional networks in alpha-proteobacteria. PLoS Comput Biol 2(12):e163. doi:10.1371/journal.pcbi.0020163

Santos JA, Alonso-García N, Macedo-Ribeiro S, Pereira PJB (2014) The unique regulation of iron-sulfur cluster biogenesis in a Grampositive bacterium. Proc Natl Acad Sci USA 111:E2251-E2260

Simões CMO, Spitzer V (1999) Óleos voláteis. In: Simões CMO, Schenkel EP, Gosmann G, de Mello JCP, Mentz LA, Petrovick PR (eds) Farmacognosia: da planta ao medicamento, 6th edn. UFRGS, Porto Alegre, pp 387-416

Soni KA, Nannapaneni R, Tasara T (2011) The contribution of transcriptomic and proteomic analysis in elucidating stress adaptation responses of Listeria monocytogenes. Foodborne Pathog Dis 8:843-852

Swint-Kruse L, Matthews KS (2009) Allostery in the LacI/GalR family: variations on a theme. Curr Opin Microbiol 12:129-137

Trapnell C, Roberts A, Goff L, Pertea G, Kim D, Kelley DR, Pachter L (2012) Differential gene and transcript expression analysis of RNAseq experiments with TopHat and cufflinks. Nat Protoc 7:562-578

Trémoulet F, Duché O, Namane A, Martinie B, Labadie JC, European Listeria Genome Consortium (2002) Comparison of protein patterns of Listeria monocytogenes grown in biofilm or in planktonic mode by proteomic analysis. FEMS Microbiol Lett 210:25-31

Upadhyay A, Upadhyaya I, Kollanoor-Johny A, Venkitanarayanan K (2013) Antibiofilm effect of plant derived antimicrobials on Listeria monocytogenes. Food Microbiol 36:79-89

Vandesompele J, De Preter K, Pattyn F, Poppe B, Van Roy N, De Paepe A, Speleman F (2002) Accurate normalization of real-time quantitative RT-PCR data by geometric averaging of multiple internal control genes. Genome Biol Res:0034.1-0034.11

Vasconcelos JA, Deneer HG (1994) Expression of superoxide dismutase in Listeria monocytogenes. Appl Environ Microbiol 60:2360-2366

Williams T, Joseph B, Beier D, Goebel W, Kuhn M (2005) Response regulator DegU of Listeria monocytogenes regulates the expression of flagella-specific genes. FEMS Microbiol Lett 252:287-298

Xayarath B, Freitag NE (2012) Optimizing the balance between host and environmental survival skills: lessons learned from Listeria monocytogenes. Future Microbiol 7:839-852

Yamada T, Letunic I, Okuda S, Kanehisa M, Bork P (2011) iPath2.0: interactive pathway explorer. Nucleic Acids Res 39:W412-W415

Yang S, Xu H, Wang J, Liu C, Lu H, Liu M, Zhao Y, Tian B, Wang L, Hua $\mathrm{Y}$ (2016) Cyclic AMP receptor protein acts as a transcription regulator in response to stresses in Deinococcus radiodurans. PLoS One. doi:10.1371/journal.pone.0155010

Ye J, Fang L, Zheng H, Zhang Y, Chen J, Zhang Z, Wang J (2006) WEGO: a web tool for plotting GO annotations. Nucleic Acids Res 34:W293-W297 